\title{
Explaining Contraceptive Use Differences: Do Men Play a Role?
}

\author{
F. Nii-Amoo Dodoo*
}

\begin{abstract}
Data from the Kenya and Ghana Demographic and Health Surveys (DHS) are used to assess the observed difference in modern contraceptive use between the two countries. The findings indicate that although female fertility preferences and education remain important, differences in male fertility goals also appear to be a crucial determinant of the contraceptive gap between Kenya and Ghana. Some implications of these findings are discussed.
\end{abstract}

\section{Résumé}

Les données provenant des Enquêtes démographiques et sanitaires menées au Kenya et au Ghana sont utilisées dans l'évaluation des différences relevées dans l'utilisation des méthodes contraceptives modernes entre les deux pays. Les résultats des recherches indiquent que, bien que les choix en matière de fécondité féminine et d'éducation restent importants, les différences dans les objectifs en matière de fécondité masculine apparaissent également comme un déterminant crucial du fossé qui existe entre le Kenya et le Ghana en matière de contraception. Certaines implications des résultats des recherches ont fait l'objet d'une discussion.

\section{INTRODUCTION}

Fertility declines in sub-Saharan Africa are long overdue to the extent that recent observed changes in a handful of countries have served to curb some of the pessimism regarding the region's future. The recent declines have been welcome, also because they offer excellent opportunities to examine sources of fertility change in an African context which, until recently, were unavailable. Comparisons between countries at different stages of fertility transition (i.e., declining, rising, or stagnant) can illuminate fruitful avenues for inducing change in areas yet to experience fertility decline, areas which by far represent the bulk of the continent.

Although numerous explanations have been advanced for fertility transition, it is increasingly being acknowledged that a major explanation for the resistance of sub-Saharan Africa's fertility to change involves the general neglect of men's real dominance in reproductive, and specifically, family planning decision making (Mbizvo and Adamchak 1991, 1992). To date, there has been little empirical assessment of the degree to which men influence contraceptive adoption. This phenomenon is reflective of family planning programmes' unequivocal focus on women, and the failure to consider the dynamics of household and family decision making in the fertility arena, in societies where male dominance in this realm has been extensively documented.

Further, although a handful of studies have measured the effect of men's roles at the local level, none exists at the national level. This study seeks to address this omission by assessing the extent to which both men's and women's reproductive preferences are associated with contraceptive use in two sub-Saharan African countries, Ghana and Kenya. These two countries provide an interesting comparison; although they were the first two in sub-Saharan Africa to institute national family planning programmes (and at approximately the same time) they are currently experiencing vastly different fertility and contraceptive use trends (National Council for Population and Development and the Institute for Resource Development [IRD] 1989; Ghana Statistical Service and IRD 1989).

\section{Fertility and Family Planning in Ghana and Kenya}

Kenya and Ghana, two countries on the east and west coasts of Africa, respectively, have historically exhibited some of the highest fertility levels in the world. However, recent estimates peg Kenya's total fertility rate (TFR) at 5.4 children per woman, and Ghana's at 6.2 (Population Reference Bureau [PRB] 1993a, 1993b), figures reflecting the recent fertility trends in the two countries. Kenya's fertility 
has fallen rapidly from the 8.1 children per woman reported in the 1977-78 Kenya World Fertility Survey (WFS). On the other hand, the 1979 Ghana WFS recorded a TFR of 6.3 children per woman.

The trends are also reflective of contraceptive use patterns in the two countries. In Ghana, modern contraceptive use has been stagnant at around 5 per cent over the last 15 years, whereas Kenya has seen a remarkable increase from 4.3 per cent in 1977-78 to 27.3 per cent in 1993 . The corresponding 20 percent decline in Kenyan fertility from 1989 to 1993 is, consequently, the fastest national fertility decline ever recorded (PRB 1993a).

Although Kenya and Ghana are similar in terms of the inception of their family planning programmes in the late 1960's, the development and implementation of family planning policies in the two countries have diverged. After a shaky start, notable improvements were made in the Kenyan family planning programme by the mid-1980s. In Ghana, however, process was slow and small, and it was only in the late 1980's that evaluations of the national policy even began (Center for Development Research [CDR] 1990; Frank and McNicoll 1987; Lapham and Mauldin 1985; Ministry of Finance and Economic Planning [MFEP] 1992).

How much of the observed difference in contraceptive use between the two countries can be explained by differences in the quality of the national programmes? Although we can not directly answer this question with these data, we argue that extra-programmatic factors must also be significant because the improvements in the Kenyan programme, dated around the mid-1980's, could hardly have had enough time to be exclusively responsible for the sharp use differences observed by 1988-1989, when the data were gathered.

Changes in fertility and contraceptive use in Kenya have been attributed to increases in female education, and the proportion of women who want to cease childbearing (Njogu 1991). Yet, Dodoo (1992) has argued that a sizeable proportion of Ghanaian women also state a desire to cease childbearing, begging the question as to why similar fertility change has not occurred in Ghana. Statistics also show that a larger proportion of Ghanaian (than Kenyan) women attain higher, and especially tertiary, levels of education, although more Kenyan women have ever-attended school (World Bank 1988). This study should help ascertain the extent to which fertility differences between Ghana and Kenya can be explained by differences in the relative situations of women in the two countries.

\section{The Role of Men in Reproductive Decision Making}

Even the broadest of explanatory frameworks regarding fertility (for example, Davis and Blake 1956; Easterlin 1975) have focused primarily on female characteristics at the point of empirical assessment (DeGraff 1991). Njogu (1991), for instance, attributed demographic change to female education and reproductive desires without considering male desires.

As indicated earlier, researchers are becoming increasingly convinced that a major shortcoming of the analysis and policy pertinent to fertility-related behaviour in Africa is the limitation of these realms to women (Dodoo 1993a, 1993b; Dodoo and Seal 1994; Ezeh 1991, 1992). These researchers argue that such a restriction is odd, given what we know about gender roles and fertility decision making in the African context. First, fertility-related decisions involve at least two partners (Beckman 1983; Blumberg 1988; Oppong 1987). Further, although macro-level indicators point to negligible gender differences in reproductive goals (Mason and Taj 1987), there is rationale for, and evidence of, substantial variation among spouses (Caldwell 1983; Dodoo and Seal 1994; Fapohunda and Todaro 1988; Lesthaeghe 1989; Mott and Mott 1985). Finally, significant evidence attests to the fact that gender power relations in the region skew decision making power in men's favour, and against women (Beckman 1983; Frank and McNicoll 1987; Hollerbach 1980; Khalifa 1988; Mustafa and Mumford 1984).

\section{DATA AND METHODS}

The data for the study come from the 1988 Ghana and 1989 Kenya DHS which, in addition to general background information, provide data on contraceptive use, and the reproductive intentions of 
spouses, both male and female. The standardized format of these surveys permits reasonable comparison of variables across countries.

The analysis is restricted to married women in the two samples whose husbands were also interviewed, a condition that permits the matching of 1,189 Kenyan and 1,010 Ghanaian spousal pairs, because polygamous men are matched with each of their interviewed spouses. A further restriction excludes women who are known to be infecund, leaving 1,145 Kenyan and 971 Ghanaian dyads. Unfortunately, neither survey includes a representative sample of men in the country, because male selection involved husbands of subsamples of interviewed women. Although, this procedure provides room for bias in the comparison, not much can be done to rectify the problem.

The data also offer little opportunity to undertake a comprehensive examination of the exhaustive list of factors that condition the observed differences in contraceptive use. Most notably, there is no apparent means to examine differences in supply-side explanatory factors, (for example, the programmatic and policy differences regarding how the two programmes actually differ in coverage and application). With these constraints in mind, the focus of this article remains an attempt to examine the extent to which differences in certain measured demand-related characteristics especially male and female preferences, and education - explain the gap in contraceptive use between Kenya and Ghana.

\section{Variable Selection}

The dependent variable, the prevalence of modern contraception, is scored ' 1 ' when respondents report current use, and ' 0 ' otherwise. We focus on modern methods because they play a more effective role in fertility decline, and also because they remain the focus of family planning programmes.

The explanatory variables in the model reflect comparable demographic and socioeconomic variables that affect contraceptive use. Age, measured as a continuous variable, is expected to manifest itself most on contraceptive use when fecundity is highest, suggesting that use may be lowest in the middle reproductive years when exposure to pregnancy is highest (Njogu 1991). Experience with previous child mortality should be negatively associated with contraceptive use, as parents attempt to replace deceased children (Tuladhar 1985). This variable is dichotomous, coded ' 1 ' if a woman has experienced child mortality in the past, and ' 0 ' if otherwise. Marital status is a three-category dummy variable reflecting monogamous (coded ' 0 ') versus polygamous marriage; in the latter, a distinction is made between senior and junior wives. The hypothesis is that women in polygamous marriages are less likely to use modern forms of contraception. Urban/rural residence is scored ' 1 ' for urban dwellers, and ' 0 ' for their rural counterparts. Urban areas typically offer residents more access to contraceptive and other services.

Covariates of interest in this study include female education which has been widely noted for its fertility depressing effect (see, for example, Caldwell 1980). The variable has three categories: no schooling; at least some primary schooling; and, at least some secondary schooling. Men's education is coded similarly; although, the education of men is typically neglected in such analyses, we anticipate that more educated men have greater awareness of the costs and benefits of contraception. Also, their higher ambition for their children is expected to manifest itself in a desire to lower fertility.

The fertility preferences of women are also of interest here. As stated earlier, Njogu (1991) attributed contraceptive adoption in Kenya to an increase in the number of women who want no more children, thus, preferences are coded to reflect respondents' potential contraceptive needs. Women have 'no need' for contraception if they indicate that they want to have a or indeed another child within two years. If women report indecision about preferences, or state that they do want another child, albeit after a two-year wait, they are classified as having a 'spacing need'. Finally, women who want to cease childbearing altogether are categorized as having a 'stopping need'. Male preferences are coded similarly. The rationale for including men's reproductive preferences derives from the dominant role of men in reproductive decision making in sub-Saharan Africa (Dodoo 1993b; Ezeh 1992). 
Obviously, other variables contribute to the observed national differences in contraceptive use. However, these are not accounted for here for two reasons. First, as indicated earlier, the nature of the data prescribes the limits of variable selection. Second, the variables were carefully chosen to retain comparability to other recent studies. There is no pretence to specify a model that fully explains the differences in contraceptive use. What we do investigate is the extent to which differences in the levels of these measured variables contribute to the observed variance in contraceptive use between the two countries.

\section{The Analytical Model}

The dichotomous nature of the dependent variable makes it amenable to a logistic regression model. The log odds of modern contraceptive use are expressed as a summation of the products of covariate means $(\mathrm{X})$, and the regression coefficients (b). Thus, for a given country $\mathrm{c}$, the log odds are estimated as:

$\operatorname{Logit}_{c}=\operatorname{Ln}\left(\mathrm{p}_{\mathrm{i}} /\left[1-\mathrm{p}_{\mathrm{i}}\right]\right)=\Sigma \mathrm{b}_{\mathrm{i}} \mathrm{X}_{\mathrm{i}}$

In the ensuing decomposition analysis, a method described in Althauser and Wigler (1972), Iams and Thornton (1975), and Jones and Kelley (1984) is used to partition the observed difference in contraceptive use between Kenya and Ghana. The analytical formula is:

$$
\begin{gathered}
L_{K}-L_{G}=\left(a_{K}-a_{G}\right)+\sum b_{i G}\left(X_{i K}-X_{i G}\right)+\sum X_{i G}\left(b_{i K}-b_{i G}\right) \\
+\Sigma\left(X_{i K}-X_{i G}\right)\left(b_{i K}-b_{i G}\right)
\end{gathered}
$$

where,

$\mathrm{L}=$ logit for a given country

$\mathrm{K}=$ Kenya, the reference category

$\mathrm{G}=$ Ghana

$\mathrm{a}=$ intercept

$\mathrm{X}_{\mathrm{i}}=$ mean of ith attribute

$b_{i}=$ partial slope of ith attribute

The first component, measuring the difference in intercepts, corresponds to the portion of the variance in contraceptive use between the two countries not explained by variables in the model. The second component reflects the portion of the contraceptive difference explained by compositional variation in the regressors, and recognizes that the contraceptive difference can, in part, be attributed to variations in the characteristics that influence contraceptive use. In addition, it is plausible to argue that the contraceptive impact of possessing these attributes differs between the countries, and the relative contribution of this factor is represented by the third component which measures slope (propensity), or "rate of return" differences. The fourth (interaction) component reflects the covariation between endowments and slopes in the two countries.

\section{RESULTS}

\section{Descriptive Analysis}

The data in table 1 document interesting variations between the Kenyan and Ghanaian samples. Compared to Ghanaian women, Kenyan women are slightly older, less likely to have dead children, or be in polygamous marriages. These factors should incline Kenyan women more towards contraception. On the other hand, women in the Ghanaian sample are considerably more urban.

Further comparison of the two samples reveals higher educational levels for both women and men in Kenya. The fertility preferences (and contraceptive needs) of Kenyan women are also more reconcilable with lower fertility than those of their Ghanaian counterparts. Kenyan women are more likely to want to cease childbearing, while Ghanaian women appear to be most interested in spacing 
their births. Dodoo (1995) has indicated that in Ghana, women are more likely to lean towards traditional methods to meet their spacing needs, but to modern methods when they want to stop childbearing. With modern contraceptive use levels at 17 per cent in Kenya in 1989, and 5 per cent in Ghana in 1988, it would be easy to surmise that the observed reproductive preference differences reflect the primary reasons for the observed contraceptive gap. However, the differences in male contraceptive needs are at least as glaring as those noted for females. More than 48 per cent of Kenyan men want no more children, while only 18 per cent of Ghanaian men have this desire. Interestingly, although a higher proportion of Ghanaian men, than women, have no need for contraception (that is, they want more children within two years), the reverse holds true for Kenya.

Although these variations probably contribute to the observed contraceptive prevalence differences, the propensities associated with these variables could also differ between the two countries. Table 2 examines bivariate relationships between the selected variables and contraceptive use. With very few exceptions, contraceptive use has the expected relationships with the explanatory variables in both countries. However, the selected characteristics have larger impacts on contraceptive use in Kenya. How much of the contraceptive gap is attributable to: a) the different distributions of men and women across the selected characteristics, between the two countries; and b) differences in the impacts of these variables on contraceptive use? These questions will be addressed in the decomposition analysis.

\section{Multivariate Analysis}

In order to explain the factors responsible for the contraceptive prevalence difference between Ghana and Kenya, it is useful to identify the determinants of contraceptive use in the two countries. A multivariate model examining the effects of the independent variables on contraceptive use allows us to disentangle the potentially confounding effects of the various regressors on the dependent variable. The logit estimates from the model are presented in table 3. For each country, two sets of estimates are provided; the first reflects the traditional model limited to female variables, while the second incorporates male characteristics.

The estimates presented in columns one and two indicate that primary schooling of females, and urban residence, are positively associated with contraceptive use across the board. The effects of urbanization and primary schooling appear larger in Ghana than in Kenya. Perhaps, because family planning is more diffuse in Kenya there is less urban and educational variability. Similarly, the considerably larger proportion of Ghanaian (than Kenyan) women who have never attended school, manifests itself in a sharper impact of primary schooling. Secondary schooling is significant only in the Kenyan case. As well, with regard to fertility preferences, there is a significant impact on modern contraceptive use in Ghana only when women feel the need to cease childbearing (Dodoo 1995), whereas the spacing coefficient is also significant in Kenya.

Columns three and four include male schooling and preferences. Male education is not a significant determinant of contraceptive use. Men's reproductive preferences, however, are clearly important. In Ghana, male preferences are associated with use for spacing, whereas in Kenya both spacing and stopping preferences raise contraceptive use significantly.

A much higher proportion of men in Kenya (than Ghana) want to cease childbearing, and their preferences have a significant effect on their spouses' contraceptive use. A plausible explanation may lie in lineage differences between the two countries; while close to one-half of Ghana is matrilineal, Kenyan ethnic groups are primarily patrilineal, making it conceivable that male preferences play a larger role in Kenya than in Ghana (Caldwell and Caldwell 1993; Vellenga 1986). Explanations centred around the traditional family and lineage systems surrounding marriage are viable because these forms of social organization manifest themselves in potentially different reproductive goals for spouses (Frank and McNicoll 1987; Lesthaeghe 1989). The extent to which these differences can be negotiated and resolved among reproductive partners differs between patrilineal and matrilineal societies. In the latter, the traditional authority of men in decisions regarding sex and reproduction is considerably attenuated (Caldwell and Caldwell 1993; Vellenga 1986). Unfortunately, the data at hand, and most of those currently available, do not permit direct assessment of these features of African society, so that it may be useful for future data-gathering efforts to be more sensitive to the peculiar cultural contexts. 
The significance of including male variables can also be imputed from their impact on female variable effects. For one thing, their inclusion attenuates the effects of urbanization and female education, suggesting that some of these effects should really be credited to male preferences. Similarly, the effects of female preferences are reduced in Kenya, and completely lose significance in Ghana.

The importance of male and female preferences leads us to explore the formulation of a joint measure of contraceptive need. The three preference categories are cross-classified for men and women. Table 4 presents the resulting nine categories with their associated levels of contraceptive use. The modal category in Kenya is one in which both spouses want to cease childbearing, or have a (stopping) need for contraception. More than 40 per cent of Kenyan dyads are in this category which, logically, also has the highest level of contraceptive use (31 per cent). Similar Ghanaian pairs do not represent the modal category, although they remain the most prolific contraceptors (approximately 12 per cent). In Ghana, the modal category is one in which both spouses have a spacing need (41 per cent), a category characterized by lower contraceptive use ( 6 per cent).

A close inspection of table 4 reveals that, in Kenya contraceptive use levels are at their highest (31 per cent and 23 per cent) when men want to cease childbearing, and their wives also either want to stop or space their fertility. The next highest use levels occur when men want to space (18 per cent and 17 per cent), and their wives want to stop or space. On the other hand, when women want to cease childbearing, the proportions who use contraception equal 31 per cent and 18 per cent when their husbands want to stop or space, respectively. When women want to space their childbearing, the relevant proportions are 23 per cent and 17 per cent, depending on whether their husbands want to stop or space. Use is much higher when men want to stop and their wives want to space (23 per cent), than it is when women want to stop and their husbands want to space (18 per cent).

A similar examination of the ranking of use levels in Ghana suggests that Ghanaian men apparently have less influence than Kenyan men, on women's contraceptive use. The highest use levels $(12,11$, and 8 per cent) are associated with female preferences to cease childbearing. When men in Ghana want to cease childbearing, use is at 4 per cent when their spouses want to space, and nil when their wives want children within two years, implying that contraceptive use is more reflective of female (than male) preferences in Ghana.

\section{Decomposition Analysis}

In this section we attempt to separate the influences of composition or endowment differences between the two countries, from propensity (slope) differences. The results of this decomposition analysis, presented in table 5 , indicate that the primary component of the difference (47 per cent) is attributable to propensity, which comprises intercept and slope effects. By far, the largest contribution to this is from the intercept, which signals the importance of unmeasured variables such as differences in the density of, and access to, family planning services.

Differences in the "rate of return" to men's preferences (slopes) also contribute to the observed gap. When men in Kenya want to cease childbearing, contraceptive use returns are higher than in Ghana. Perhaps, Kenyan men have greater access to family planning, such that even when men in both countries want to cease childbearing the return for Kenyan men is higher. Of course, this point is speculative and will need further empirical validation. Alternatively, men in patrilineal societies may have more of an inclination to ensure that their preferences are translated into decision making; matrilineal men may be less likely to do so because of the relatively higher ability of women (compared to patrilineal women) to govern their own behaviour. The returns to female preferences are also higher in Kenya, whereas the reverse is true for primary schooling for both men and women.

Although not as statistically prominent as propensity, composition differences still explain 28 per cent of the contraceptive gap between Ghana and Kenya. Differences in the proportion of men and women in the two countries who want to stop or cease childbearing each comprise 17 per cent of the variance, respectively.

The bottom line of table 5 provides the composition, propensity, and interaction effects of the model that excludes male variables. Including men's characteristics reduces the propensity component from 
55 per cent to 47 per cent, indicating an increase in explanatory power. The composition effect increases more significantly (from 21 to 28 per cent), however, affirming the importance of male characteristics. The implication is that, what is really a result of male attributes may be construed as an urbanization, or female variable effect, when male characteristics are excluded from the model; models that exclude the male perspective bias the relationship between contraceptive use and the traditional (female) explanatory variables.

\section{DISCUSSION}

A goal of this study was to consider the significance of including the habitual omission of male perspective in the analysis of reproductive behaviour in Ghana and Kenya. Another purpose was to examine the extent to which the sizeable contraceptive gap between Kenya and Ghana could be attributed to differences in male and female education, and fertility preferences.

The results of the analysis point to the importance of the male perspective. Although men's influence is not yet significant in Ghana, their preferences are clearly important predictors of contraceptive use in Kenya. It has been suggested elsewhere, that fertility change in countries like Ghana awaits a transition in men's desires (Dodoo 1993a; Ezeh 1991, 1992; Mbizvo and Adamchak 1991), an argument that has some merit given that 75 per cent of the women in the Ghanaian sample state a need for stopping or spacing their childbearing.

There is also, clearly, a role played by women's education and preferences. In this vein, the five-fold increase to almost universal education between 1963 and 1985 in Kenya, while Ghanaian enrolment rates stagnated in the 1970's and 1980's (Njogu 1991; World Bank 1988), has probably been instrumental in raising the level of contraceptive prevalence in Kenya.

The role of family planning programmes, although not directly measured here, apparently should not be understated. Half of the difference between the two countries derives from the propensity component, and a sizeable portion of this, from the intercept which reflects unmeasured factors such as differences in availability of, and access to, family planning. Although the Kenyan programme was rated 'weak', and the Ghanaian 'very weak' in 1982 (Lapham and Mauldin 1985), there apparently were qualitative differences that favoured Kenya. By 1989, the two programmes rated higher (moderate) and the gap between them had narrowed (Mauldin and Ross 1991).

The findings have some bearing for policy. Revitalizing the education system, particularly in countries like Ghana, where economic hardships have reversed post-independence gains appears crucial. The link between female education and reproductive preferences is well documented (see, for instance, Dodoo 1992), and our results echo recommendations for improving the status of women. Ironically, the particularly weak economies of these sub-Saharan African countries is what compels a need to search for alternate routes to fertility decline. Although, improving the status of women remains imperative, and should continue to be high on national and population agendas, the irony of the situation is that many of the countries that require this impulse are the very ones that can not, realistically, afford the levels of investment needed to attain meaningful changes in, for example, levels of female education, at least not in the near future. While attempts to elevate the status of women continue, efforts to identify other means of inducing lower fertility must also be intensified. Particularly in societies where men exercise such control over reproduction, reducing male fertility preferences seems to be a reasonable choice. Will it suffice to educate men about the benefits of contraception? Are men already cognizant of these, but, perhaps, need a nudge (for instance, in the form of taxation)? What are the most effective ways to reach men with the message of urgency? These constitute some new challenges for the future.

Table 1: Kenya-Ghana Differences in Selected Characteristics.

\begin{tabular}{|l|l|l|}
\hline Proportions: & Kenya & Ghana \\
\hline Age: & & \\
\hline
\end{tabular}




\begin{tabular}{|c|c|c|}
\hline $15-24$ & 0.186 & 0.195 \\
\hline $25-34$ & 0.406 & 0.447 \\
\hline $35-44$ & 0.329 & 0.268 \\
\hline $45+$ & 0.080 & 0.091 \\
\hline \multicolumn{3}{|l|}{ Marital status: } \\
\hline Monogamous & 0.788 & 0.693 \\
\hline Senior wives & 0.053 & 0.149 \\
\hline Junior wives & 0.159 & 0.158 \\
\hline \multicolumn{3}{|l|}{ Type of residence: } \\
\hline Urban & 0.132 & 0.229 \\
\hline Rural & 0.868 & 0.771 \\
\hline \multicolumn{3}{|l|}{ Previous child loss: } \\
\hline None & 0.669 & 0.568 \\
\hline $1+$ & 0.331 & 0.433 \\
\hline \multicolumn{3}{|l|}{ Education: } \\
\hline None & 0.368 & 0.565 \\
\hline Primary & 0.480 & 0.398 \\
\hline Secondary & 0.148 & 0.030 \\
\hline More than secondary & 0.003 & 0.007 \\
\hline \multicolumn{3}{|l|}{ Education (husband): } \\
\hline None & 0.168 & 0.394 \\
\hline Primary & 0.555 & 0.453 \\
\hline Secondary & 0.264 & 0.118 \\
\hline More than secondary & 0.013 & 0.034 \\
\hline \multicolumn{3}{|c|}{ Fertility preferences/contraceptive need: } \\
\hline No need & 0.125 & 0.211 \\
\hline Spacing need & 0.316 & 0.539 \\
\hline Stopping need & 0.558 & 0.249 \\
\hline
\end{tabular}




\begin{tabular}{|l|l|l|}
\hline No need & 0.114 & 0.228 \\
\hline Spacing need & 0.403 & 0.591 \\
\hline Stopping need & 0.483 & 0.181 \\
\hline Contraceptive use: & 0.206 & 0.059 \\
\hline Means: & \multicolumn{2}{|l|}{} \\
\hline Age & 32.30 & 31.48 \\
\hline Age (husband) & 41.97 & 40.69 \\
\hline$\underline{\text { Number of dyads }}$ & $\underline{1145}$ & $\underline{971}$ \\
\hline
\end{tabular}

Source: 1988 Ghana Demographic and Health Survey.

Table 2: Contraceptive Use by Selected Characteristics.

\begin{tabular}{|c|c|c|c|c|}
\hline & Kenya & $\underline{N}$ & Ghana & $\underline{N}$ \\
\hline \multicolumn{5}{|l|}{ Age: } \\
\hline $15-24$ & 0.147 & 213 & 0.048 & 189 \\
\hline $25-34$ & 0.204 & 465 & 0.051 & 434 \\
\hline $35-44$ & 0.249 & 376 & 0.081 & 260 \\
\hline $45+$ & 0.181 & 91 & 0.057 & 88 \\
\hline \multicolumn{5}{|l|}{ Marital status: } \\
\hline Monogamous & 0.218 & 901 & 0.066 & 671 \\
\hline Senior wives & 0.093 & 60 & 0.049 & 144 \\
\hline Junior wives & 0.183 & 182 & 0.039 & 153 \\
\hline \multicolumn{5}{|c|}{ Type of residence: } \\
\hline Urban & 0.328 & 151 & 0.113 & 222 \\
\hline Rural & 0.188 & 994 & 0.043 & 749 \\
\hline \multicolumn{5}{|c|}{ Previous child loss: } \\
\hline None & 0.228 & 766 & 0.065 & 551 \\
\hline $1+$ & 0.163 & 379 & 0.050 & 420 \\
\hline \multicolumn{5}{|l|}{ Education: } \\
\hline None & 0.120 & 421 & 0.029 & 549 \\
\hline
\end{tabular}




\begin{tabular}{|l|l|l|l|l|}
\hline Primary & 0.209 & 550 & 0.101 & 386 \\
\hline Secondary & 0.405 & 170 & 0.035 & 29 \\
\hline More than secondary & 0.505 & 4 & 0.143 & 7 \\
\hline Education (husband): & \multicolumn{5}{|l|}{} \\
\hline None & 0.141 & 193 & 0.026 & 383 \\
\hline Primary & 0.155 & 636 & 0.080 & 440 \\
\hline Secondary & 0.348 & 302 & 0.078 & 115 \\
\hline More than secondary & 0.395 & 14 & 0.091 & 33 \\
\hline Preferences/contraceptive need: & \multicolumn{5}{|l|}{} \\
\hline No need & 0.057 & 143 & 0.024 & 205 \\
\hline Spacing need & 0.158 & 362 & 0.052 & 523 \\
\hline Stopping need & 0.268 & 639 & 0.103 & 242 \\
\hline Preferences/contraceptive need (husband): & & \\
\hline No need & 0.060 & 131 & 0.018 & 221 \\
\hline Spacing need & 0.151 & 461 & 0.065 & 574 \\
\hline Stopping need & 0.287 & 553 & 0.091 & 176 \\
\hline
\end{tabular}

Source: 1988 Ghana Demographic and Health Survey.

Table 3: Logit Estimates of Contraceptive Use.

\begin{tabular}{|c|c|c|c|c|}
\hline & \multicolumn{4}{|c|}{ Model } \\
\hline & \multicolumn{2}{|c|}{ Wife-only } & \multicolumn{2}{|c|}{ Both spouses } \\
\hline & Kenya & Ghana & Kenya & Ghana \\
\hline \multirow[t]{2}{*}{ Intercept } & $-4.310^{\star *}$ & $-5.210 * *$ & $-4.644^{\star \star}$ & $-6.228^{\star \star}$ \\
\hline & $(0.568)$ & (0.871) & (0.699) & (1.014) \\
\hline \multirow[t]{2}{*}{ Age } & 0.020 & 0.029 & 0.004 & 0.034 \\
\hline & $(0.012)$ & $(0.022)$ & (0.014) & $(0.022)$ \\
\hline \multirow[t]{2}{*}{ Previous child loss (1+) } & -0.182 & -0.312 & $-0.083)$ & -0.318 \\
\hline & $(0.179)$ & $(0.318)$ & $(0.184)$ & $(0.320)$ \\
\hline
\end{tabular}




\begin{tabular}{|c|c|c|c|c|}
\hline \multicolumn{5}{|l|}{ Marital status: } \\
\hline Junior wives & $\begin{array}{l}0.055 \\
(0.221)\end{array}$ & $\begin{array}{l}-0.196 \\
(0.461)\end{array}$ & $\begin{array}{l}0.058 \\
(0.225)\end{array}$ & $\begin{array}{l}-0.079 \\
(0.465)\end{array}$ \\
\hline Senior wives & $\begin{array}{l}-0.563 \\
(0.467)\end{array}$ & $\begin{array}{l}-0.055 \\
(0.433)\end{array}$ & $\begin{array}{l}-0.503 \\
(0.475)\end{array}$ & $\begin{array}{l}-0.009 \\
(0.440)\end{array}$ \\
\hline Residence type (urban) & $\begin{array}{l}0.561^{*} \\
(0.222)\end{array}$ & $\begin{array}{l}0.707^{*} \\
(0.299)\end{array}$ & $\begin{array}{l}0.486^{*} \\
(0.232)\end{array}$ & $\begin{array}{l}0.702^{*} \\
(0.303)\end{array}$ \\
\hline Education: & & & & \\
\hline Primary & $\begin{array}{l}0.818^{\star *} \\
(0.198)\end{array}$ & $\begin{array}{l}1.152^{\star \star} \\
(0.330)\end{array}$ & $\begin{array}{l}0.602^{\star *} \\
(0.210)\end{array}$ & $\begin{array}{l}1.010^{* *} \\
(0.358)\end{array}$ \\
\hline Secondary plus & $\begin{array}{l}1.824^{\star *} \\
(0.253)\end{array}$ & $\begin{array}{l}0.338 \\
(0.807)\end{array}$ & $\begin{array}{l}1.453^{\star *} \\
(0.287)\end{array}$ & $\begin{array}{l}0.385 \\
(0.851)\end{array}$ \\
\hline Education (husband): & & & & \\
\hline Primary & & & $\begin{array}{l}-0.171 \\
(0.252)\end{array}$ & $\begin{array}{l}0.508 \\
(0.415)\end{array}$ \\
\hline Secondary plus & & & $\begin{array}{l}0.487 \\
(0.286)\end{array}$ & $\begin{array}{l}0.250 \\
(0.527)\end{array}$ \\
\hline $\begin{array}{l}\text { Preferences/contraceptive } \\
\text { need: }\end{array}$ & & & & \\
\hline Spacing need & $\begin{array}{l}1.083^{\star \star} \\
(0.399)\end{array}$ & $\begin{array}{l}0.785 \\
(0.503)\end{array}$ & $\begin{array}{l}0.944^{*} \\
(0.404)\end{array}$ & $\begin{array}{l}0.368 \\
(0.526)\end{array}$ \\
\hline Stopping need & $\begin{array}{l}1.938^{\star *} \\
(0.392)\end{array}$ & $\begin{array}{l}1.237^{*} \\
(0.518)\end{array}$ & $\begin{array}{l}1.567^{\star *} \\
(0.404)\end{array}$ & $\begin{array}{l}0.865 \\
(0.555)\end{array}$ \\
\hline $\begin{array}{l}\text { Preferences/contraceptive } \\
\text { need (husband): }\end{array}$ & & & & \\
\hline $\begin{array}{l}\text { Spacing } \\
\text { need }\end{array}$ & & & $\begin{array}{l}0.954^{*} \\
(0.395)\end{array}$ & $\begin{array}{l}1.150^{*} \\
(0.563)\end{array}$ \\
\hline
\end{tabular}




\begin{tabular}{|c|c|c|c|c|c|}
\hline & $\begin{array}{l}\text { Stopping } \\
\text { need }\end{array}$ & & & $\begin{array}{l}1.543^{\star \star} \\
(0.404)\end{array}$ & $\begin{array}{l}0.872 \\
(0.628)\end{array}$ \\
\hline$-2 \log L$ & & 1035.85 & 392.63 & 1000.61 & 385.46 \\
\hline Chi-square & & 130.37 & 41.18 & 165.62 & 48.35 \\
\hline df & & 9 & 9 & 13 & 13 \\
\hline$N$ & & 1188 & 971 & 1188 & 971 \\
\hline
\end{tabular}

Note:a. Omitted categories: previous child loss (none);

marital status (monogamous); type of residence (rural); Education (none); Preference/contraceptive need (no need--wants more children).

b. Standard errors are in parentheses.

c. * - significant at the .05 level.

d. ** - significant at the .01 level.

Source:1988 Ghana Demographic and Health Survey.

Table 4: Joint Contraceptive (Preferences) Need by Actual Use.

\begin{tabular}{|l|l|l|l|l|}
\hline & $\underline{\text { Kenya }}$ & $\underline{\mathrm{N}}$ & $\underline{\text { Ghana }}$ & $\underline{\underline{N}}$ \\
\hline Both have stopping need & 0.310 & 453 & 0.119 & 118 \\
\hline Wife space; husband stop & 0.227 & 76 & 0.044 & 45 \\
\hline Wife no need; husband stop & 0.032 & 24 & 0.000 & 13 \\
\hline Wife stop; husband space & 0.178 & 150 & 0.083 & 97 \\
\hline Both spacing need & 0.165 & 225 & 0.063 & 396 \\
\hline Wife no need; husband space & 0.059 & 84 & 0.050 & 80 \\
\hline Wife stop; husband no need & 0.089 & 35 & 0.111 & 27 \\
\hline Wife space; husband no need & 0.050 & 61 & 0.000 & 82 \\
\hline Both have no need & 0.047 & 35 & 0.009 & 112 \\
\hline Number & $\underline{1143}$ & & $\underline{970}$ & \\
\hline
\end{tabular}

Source: 1988 Ghana Demographic and Health Survey.

Table 5: Decomposition of Contraceptive Use Difference.

\begin{tabular}{|c|c|c|c|}
\hline & \multicolumn{3}{|c|}{ Proportion of Difference due to: } \\
\hline Selected covariates: & Composition & Propensity & Interaction \\
\hline Age & 0.02 & $\mid-0.61$ & |-0.02 \\
\hline
\end{tabular}




\begin{tabular}{|c|c|c|c|}
\hline $\begin{array}{l}\text { Previous child loss } \\
(1+)\end{array}$ & 0.02 & 0.06 & -0.02 \\
\hline \multicolumn{4}{|l|}{ Marital status: } \\
\hline Junior wives & -0.00 & 0.01 & -0.00 \\
\hline Senior wives & 0.00 & -0.05 & 0.03 \\
\hline $\begin{array}{l}\text { Type of Residence } \\
\text { (urban) }\end{array}$ & -0.04 & -0.03 & 0.01 \\
\hline \multicolumn{4}{|l|}{ Education: } \\
\hline Primary & 0.05 & -0.10 & -0.02 \\
\hline Secondary plus & 0.03 & 0.03 & 0.08 \\
\hline \multicolumn{4}{|l|}{ Education (husband): } \\
\hline Primary & 0.03 & $\mid-0.20$ & $\mid-0.04$ \\
\hline Secondary plus & 0.02 & 0.02 & 0.02 \\
\hline \multicolumn{4}{|c|}{ Preferences/contraceptive need: } \\
\hline Spacing need & -0.05 & 0.20 & -0.08 \\
\hline Stopping need & 0.17 & 0.11 & 0.14 \\
\hline \multicolumn{4}{|c|}{ Preferences/contraceptive need (husband): } \\
\hline Spacing need & -0.14 & $\mid-0.07$ & 0.02 \\
\hline Stopping need & 0.17 & 0.08 & 0.13 \\
\hline Intercept & - & 1.02 & - \\
\hline $\begin{array}{l}\text { Proportion of } \\
\text { difference }\end{array}$ & 0.28 & 0.47 & 0.26 \\
\hline $\begin{array}{l}\text { Proportion of } \\
\text { difference for model } \\
\text { excluding } \\
\text { maleeducation and } \\
\text { preferences }\end{array}$ & $\underline{0.21}$ & $\underline{0.55}$ & 0.21 \\
\hline
\end{tabular}

Source: 1988 Ghana Demographic and Health Survey.

\section{REFERENCES}

- $\quad$ Althauser, R., and Wigler, M. 1972. "Standardization and Component Analysis." Sociological Methods and Research 1: 98-134.

- Beckman, Linda J. 1983. "Communication, Power, and the Influence of Social Networks in Couple Decisions on Fertility." In Determinants of Fertility in Developing Countries, Volume 2, edited by R. Bulatao and R. Lee. New York: Academic Press.

- Blumberg, Rae L. 1988. "Income Under Female Versus Male Control: Hypothesis from a Theory of Gender Stratification and Data from the Third World." Journal of Family Issues 9: 51-84.

- Caldwell, John C. 1980. "Mass Education as a Determinant of the Timing of Fertility Decline." Population and Development Review 6: 225-255.

- . 1983. "Direct Economic Costs and Benefits of Children." In Determinants of Fertility in Developing Countries, Volume 1, edited by R. Bulatao and R. Lee. New York: Academic Press.

- $\quad$, and Pat Caldwell. 1993. "The Nature and Limits of the Sub-Saharan Africa AIDS Epidemic: Evidence From Geographic and Other Patterns." Population and Development Review 19: 817-848. 
- Center for Development Research. 1990. Pregnancy, Birthing and Family Planning in Kenya: Changing Patterns. CDR Research Report No. 15. Copehnagen, Denmark.

- $\quad$ Davis, K. and J. Blake. 1956. "Social Structure and Fertility: An Analytic

Framework." Economic Development and Cultural Change 4: 211-235.

- DeGraff, Deborah. 1991. "Increasing Contraceptive Use in Bangladesh: The Role of Supply and Demand Factors." Demography 28: 65-81.

- Dodoo, F. Nii-Amoo. 1992. "Female Education, Age, Parity, and Reproductive Cessation in Ghana." Social Biology 39: 102-108.

- . 1993a. "A Couple Analysis of Micro-Level Supply/Demand Factors in Fertility Regulation." Population Research and Policy Review 12: 93-101.

- . 1993b. "The Couple KAP-gap: Implications for Family Planning." Paper presented at the Annual Meetings of the Population Association of America. Cincinnati, Ohio.

- . 1995. "Contraceptive Behaviour in Sub-Saharan Africa: A Two-Sex Model." International Journal of Sociology of the Family 25: 43-61.

- $\quad$, and Arna Seal. 1994. "Explaining Spousal Differences in Reproductive Preferences: A Gender Inequality Approach." Population and Environment 15: 379-394.

- Easterlin, R. 1975. "An Economic Framework for Fertility Analysis." Studies in Family Planning 6: 54-63.

- Ezeh, Alex. 1991. "Gender Differences in Reproductive Orientation in Ghana: A New Approach to Understanding Fertility and Family Planning Issues in sub-Saharan Africa." Paper presented at the Demographic and Health Surveys World Conference. Washington, D.C.

- . 1992. "Contraceptive Practice in Ghana: Does Partner's Attitude Matter?" Paper presented at the Annual Meetings of the Population Association of America. Denver, Colorado.

- Fapohunda, Eleanor and Michael Todaro. 1988. "Family Structure and Demand for Children in Southern Nigeria." Population and Development Review 14: 571-596.

- Frank, Odile and Geoffrey McNicoll. 1987. "An Interpretation of Fertility and Population Policy in Kenya." Population and Development Review 10: 209-243.

- Ghana Statistical Service and the Institute for Resource Development. 1989. Ghana Demographic and Health Survey, 1988. Columbia, Maryland: GSS and IRD.

- Hollerbach, Paula. 1980. "Power in Families, Communication, and the Fertility DecisionMaking." Population and Environment 3: 146-173.

- $\quad$ lams, H. H. and Thornton, A. 1975. "Decomposition of Differences: A cautionary note." Sociological Methods and Research 47: 727-739.

- Jones, F. L. and Kelley, J. 1984. "Decomposing Differences Between Groups: A cautionary note on measuring discrimination." Sociological Methods and Research 12: 323-343.

- Khalifa, M. 1988. "Attitudes of Urban Sudanese Men Toward Family Planning." Studies in Family Planning 19: 236-243.

- Lapham, R. J. and P. W. Mauldin. 1985. "Contraceptive Prevalence: The Influence of Organized Family Planning Programs." Studies in Family Planning 16: 117-137.

- Lesthaeghe, R. J. 1989. "Social Organization, Economic Crises and the Future of Fertility Control in Africa." Pp. 165-198 in Reproduction and Social Organization in Sub-Saharan Africa, edited by R. J. Lesthaeghe. Berkeley: University of California Press.

- $\quad$ Mason, Karen and Anju Taj. 1987. "Differences Between Women's and Men's Reproductive Goals in Developing Countries." Population and Development Review 13: 611-638.

- Mauldin, W. P. and J. Ross. 1991. "Family Planning Programs: Efforts and Results 198289." Studies in Family Planning 22: 350-367.

- Mbizvo, Michael and Donald Adamchak. 1991. "Family Planning Knowledge, Attitudes, and Practices of Men in Zimbabwe." Studies in Family Planning 22: 31-38.

- . 1992. "Male Fertility Regulation: A Study on Acceptance Among Men in Zimbabwe." The Central African Journal ofMedicine 38: 52-57.

- Ministry of Finance and Economic Planning. 1992. In-Depth Assessment of the Ghana National Family Planning Program: 1970-1990. Accra, Ghana.

- Mott, Frank and Susan Mott. 1985. "Household Fertility Decisions in West Africa: A Comparison of Male and Female Survey Results." Studies in Family Planning 16: 88-99.

- Mustafa, M. and S. Mumford. 1984. "Male Attitudes Towards Family Planning in Khartoum, Sudan." Journal of Biosocial Science 16: 437-450. 
- National Council for Population and Development and the Institute for Resource Development. 1989. Kenya Demographic and Health Survey. Columbia, Maryland: NCPD and IRD.

- Njogu, Wamucii. 1991. "Trends and Determinants of Contraceptive Use in Kenya." Demography 28: 83-99.

- Oppong, Christine. 1987. Sex Roles, Population and Development in West Africa: PolicyRelated Studies on Work and Demographic Issues. London: James Curry.

- Population Reference Bureau. 1993a. "Kenya Fertility Update." Population Today 21(12): 8, December.

- . 1993b. "Spotlight: Ghana." Population Today 21(7/8): 11, July/August.

- Tuladhar, J. 1985. "Determinants of Contraceptive Use in Nepal." Journal of Biosocial Science 17: 185-193.

- Vellenga, D. 1986. "Matriliny, Patriliny, and Class Formation Among Women Cocoa Farmers in Two Rural Areas of Ghana." Pp. 62-77 in Women and Class in Africa, edited by Claire Robertson and Iris Berger. New York: Africana Publishing Company.

- World Bank. 1988. Education in Sub-Saharan Africa: Policies for Adjustment, Revitalization, and Expansion. Washington, DC: World 